\title{
What Lies Beneath: Clinical and Resource-use Characteristics of Institutionalized Older People. A Retrospective, Population-based Cohort Study in Catalonia
}

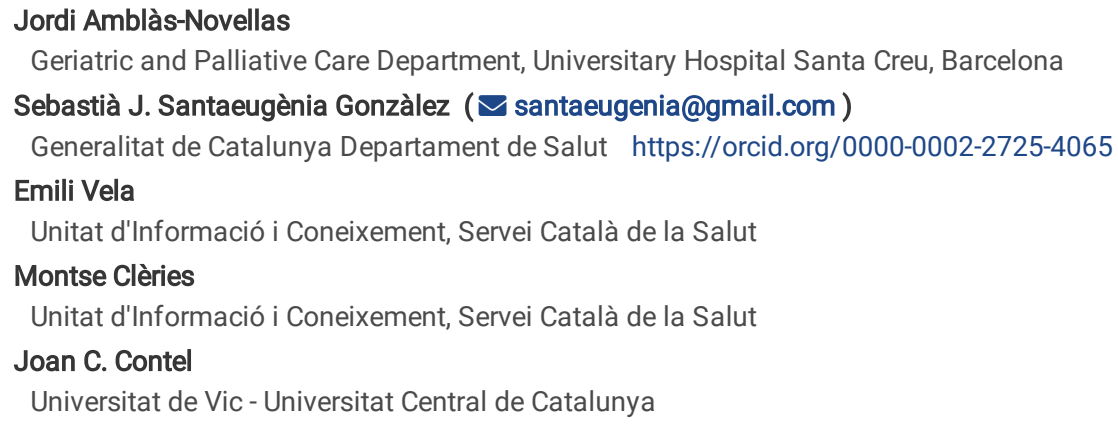

Version of Record: A version of this preprint was published at BMC Geriatrics on June 2nd, 2020. See the published version at https://doi.org/10.1186/s12877020-01587-8. 


\section{Abstract}

Background Planning population care in a specific health care setting requires deep knowledge of the clinical characteristics of the target care recipients, which tend to be country specific. Our area virtually lacks any descriptive, far-reaching publications about institutionalized older people (IOP). We aimed to investigate the demographic and clinical characteristics of institutionalized older people (IOP) $\geq 65$ years old and compare them with those of the rest of the population of the same age.

Methods Retrospective analysis (total cohort approach) of clinical and resource-use characteristics of IOP and non-IOP older than 65 years in Catalonia (North-East Spain). Variables analysed included age and sex, diagnoses, morbidity burden-using Adjusted Morbidity Groups (GMA, Grupos de Morbilidad Ajustada)-, mortality, use of resources, and medications taken. All data were obtained from the administrative database of the local healthcare system.

Results This study included 93,038, 78,458, 68,545 and 67,456 IOP from 2011, 2013, 2015 and 2017, respectively. In this interval, an increase in median age (83 vs. 87 years), in women ( $68.64 \%$ vs. $72.11 \%$ ) and in annual mortality ( $11.74 \%$ vs. $20.46 \%)$ was observed. Compared with non-IOP ( $p<0.001$ in all comparisons), IOP showed a higher annual mortality ( $20.46 \%$ vs. $3.13 \%)$, a larger number of chronic diseases (specially dementia: $46.47 \%$ vs. $4.58 \%$ ), higher multimorbidity ( $15.2 \%$ vs. $4.2 \%$ with GMA of maximum complexity), and annual admissions to acute care ( $47.6 \%$ vs. $27.7 \%)$ and skilled nursing facilities ( $27.8 \%$ vs. $7.4 \%)$, mean length of hospital stay (10.0 vs. 7.2 days) and mean of medications taken (11.7 vs. 8.0 ).

Conclusions There is a growing gap between the clinical and demographic characteristics of age-matched IOP and non-IOP, which overlaps with a higher mortality rate of IOP. The profile of resources utilization of IOP compared with non-IOP strongly suggests a deficiency of preventive actions and stresses the need to rethink the care model for IOP from a social and health care perspective.

\section{Background}

The persistently announced "epidemiological tsunami" of a great number of people of advanced age with multiple comorbidities, chronic conditions, and complex care needs is already a reality in our setting [1]. Besides the unquestionable impact on the quality of life of the people affected, organizational and/or economic repercussions of this "new reality" on health and social systems are also undeniable due to the use of resources and costs derived from care, as well as dependency- and disability-associated costs.

Beyond the fact that health systems need to keep promoting strategic measures to prevent or delay the occurrence of chronic diseases and disabilities [2], it is also essential to confront the reality of the most vulnerable people, who have high care needs and often reside in nursing homes. Based on the data available, during the first decade of the $21^{\text {st }}$ century, there was a $150 \%$ increase in the number of nursing home beds, going from 37,281 in 2000 to 93,038 in 2011 in

Catalonia [3]. This trend has been observed in most European countries, although it seems to have stabilized after 2011 [4].

Besides a higher global demand of nursing home beds, analysing the epidemiological and clinical characteristics of institutionalized people and assessing their needs, values and preferences are increasingly becoming central in the care model design for nursing homes. In 2013, Morley et al. already pointed out the need to research the care and characteristics of institutionalized people [5]. Since then, several analyses — most of them led by Gordon's group — have provided information about their health status, the effectiveness of health care models in care homes, and competencies and future challenges that should be faced in upcoming years [6]. International evidence suggest that the sociodemographic profile of institutionalized people has evolved in the last decades alongside the demographic shift $[7,8]$. However, these trends cannot be confirmed in many countries that-like Spain-lack data from care facilities. Furthermore, the absence of quantitative data on the type and extent of resource utilization of residents admitted to care facilities in our area leaves policymakers with little options other than models from other countries (often heterogeneous in terminology and type of healthcare provided) to plan service provision in this setting.

Faced with this scenario, some authors have stressed the need to gather country-specific information about institutionalized patients to better understand the factors that influence mortality and morbidity and, therefore, the needs of these care models [9]. In response to this unmet need, "The Prevention and Attention to Chronicity Program" from Catalonia's health system (northwest of Spain) has recently included an analysis of the characteristics and needs of institutionalized older people with three initial objectives: 1) describe the evolution-in the last seven years-of epidemiological and clinical characteristics and the mortality of institutionalized older people (IOP) $\geq 65$ years; 2 ) compare these characteristics with those of non-institutionalized older people (non-IOP) $\geq 65$ years; and 3) compare the use of resources between IOP and non-IOP. Objectives 2) and 3) are expected to provide useful information for identifying and quantifying the differential needs of IOP compared to non-IOP.

\section{Methods}

\section{Study Design, Participants, Data Source}

This was a retrospective analysis of an administrative database that included all people $\geq 65$ years in Catalonia (northwest of Spain) between 2011 and 2017. IOP were identified by using pharmaceutical dispensing coding data, which are necessary and specific to these people. Those subjects that in the year of inclusion had been living in a nursing home were considered IOP. Within the context of this study, and based on the consensus of the "Integrated medical care model for older people residing in nursing homes", promoted by the local health authorities, the term "nursing home" was defined as any permanent or temporary place for people $\geq 65$ years that do not have a sufficient degree of autonomy to perform daily activities, need constant supervision and live in a social-family situation requiring the replacement of their home.

Sociodemographic and clinical data were obtained from the Catalan Health Surveillance System (CHSS) that, since 2011, collects detailed information about the use of health care of the entire population of Catalonia. This record, which has been analysed in previous publications in other areas [10,11], collects data

Page $2 / 10$ 
about hospitalizations, primary care, specialized nursing care centres and mental health networks, information about prescriptions and pharmacy expenses, and a record of invoices, including outpatient visits, specialists, visits to the Emergency Room, non-urgent medical transportation, ambulatory rehabilitation, home oxygen therapy and dialysis. No data about hospital care in private health centres could be collected because these centres use different codes for patient identification.

\section{Variables}

Age and sex were the demographic variables used in the study. Clinical variables included diagnoses, as they appear in the CHSS database based on the normal course of clinical practice, and coded according to the International Classification of Diseases, ninth revision, Clinical Modification (ICD-9-CM). The comorbidity burden was stratified based on the Adjusted Morbidity Groups (GMA, Grupos de Morbilidad Ajustada), which considers the type of disease-acute or chronic-, number of systems affected, and complexity of each disease, enabling to classify people in four strata based on their morbidity-associated risk: 1) Initial risk (healthy stage), with a GMA score up to the $50^{\text {th }}$ percentile of the total population; 2 ) Low risk, with a GMA score between the $50^{\text {th }}-80^{\text {th }}$ percentiles; 3 ) Moderate risk, with a GMA score between the $80^{\text {th }}-95^{\text {th }}$ percentiles; and 4) High risk, with a GMA score above the $95^{\text {th }}$ percentile [12,13].

In order to describe the evolution of epidemiological and clinical characteristics and the mortality of IOP $\geq 65$ years, a study of biannual, cumulative prevalence was conducted. The characteristics of IOP $\geq 65$ years were compared with those of non-IOP in the same age group. The use of health resources between both groups for 2017 was also compared.

\section{Statistical Methods}

Categorical variables were described as numbers and percentages, whereas continuous variables were described as the mean and standard deviation (SD) and the median and interquartile range (IQR, defined by the $25^{\text {th }}$ and $75^{\text {th }}$ percentiles). Categorical variables were compared using the chi-square test. After confirming that all continuous variables followed a non-normal distribution (Kolmogorov-Smirnov test), we used the non-parametric Mann-Whitney U test for investigating between-group differences in these variables. The threshold of statistical significance was set at a bilateral alpha value of 0.05 . All analyses were performed using the SPSS statistical software (IBM SPSS Statistics for Windows, Version 22.0. Armonk, NY: IBM Corp.).

\section{Results}

\section{Evolution of Epidemiological and Clinical Characteristics of Older People Institutionalized in Nursing Homes}

During the seven-year interval analysed (2011-2017), the number of IOP tended to decrease, with a $27.5 \%$ reduction. IOP demographic, morbidity and mortality characteristics, summarized in Table 1, also changed during the analysed period. The prevalence of female subjects progressively increased by $3.5 \%$, and the mean age and mortality increased by 3.9 years and $8.7 \%$, respectively. Likewise, during the years under study, the prevalence of certain diseases in IOP increased, including heart failure (10.5\%), COPD (3.0\%), asthma (2.0\%), chronic renal failure (14.7\%), dementia (13.1\%), depression (20.9\%), strokecerebrovascular accident-(11.9\%), chronic diseases of the musculoskeletal system (16.5\%) and decubitus ulcers (3.3\%). On the contrary, throughout the seven years analysed, non-IOP demographic, morbidity and mortality characteristics did not undergo any relevant changes (Table 1 ).

The analysis-narrowed down to 2017-showed age and sex distribution differences between IOP and non-IOP (Figure A1, Additional file 1), as well as differences in the prevalence of diseases and chronic conditions between both sexes, of which cardiac failure was the most prevalent with no statistically significant differences between women and men (Figure A2, Additional file 1). On the other hand, the analysis of the comorbidity burden using GMA narrowed down to 2017 showed differences in the proportion of IOP and non-IOP assigned to a certain risk, with $51 \%$ for the IOP high-risk population (Figure 1).

\section{Comparative Study of Health Resource Use Based on Location}

Regarding resource use by non-IOP and IOP (Table 2), significant differences were found in the annual percentage of acute care admissions (27.7\% vs. $47.6 \%$ ) -an even higher difference if only the percentage of urgent admissions is considered (13.6 vs $40.3 \%$ ) -as well as in mean stay in these centres ( 7.2 vs. 10.0 days). There were also differences in the percentage of admissions to nursing skilled facilities ( $7.4 \%$ vs. $27.8 \%)$. On the contrary, the number of contacts with Primary Care teams had a difference of only 0.11 points between both groups. Regarding the medications taken, significant differences were detected in the number of medications taken and containers dispensed (Table 2).

\section{Discussion}

Data obtained in this observational, retrospective study, including all IOP $\geq 65$ years or non-IOP from nursing homes of Catalonia during 2011-2017, show an increase in IOP mean age and women proportion. Despite observing a reduction in the total number of IOP in our region, these people show greater morbidity, mortality and resource use than non-IOP.

The lack of consensus to define the concept of "nursing home" [14] makes it difficult to compare results from different studies conducted at a national and international level. However, Spain's official data indicate that the prevalence of IOP in the region where the study was conducted is notably higher than in the rest of the country: $5.9 \%$ vs. $3.7 \%$ of the total population $\geq 65$ years, respectively [15]. Furthermore, although Spanish data indicate an increase of IOP in the first decade of the century, our data show a progressive reduction-from $7.4 \%$ in 2011 to $4.8 \%$ in $2017-$, a fact that could be related with the economic crisis and the difficulty to afford a nursing home [16]. Regardless of the reasons that may explain this trend, during the second decade of the $21^{\text {st }}$ century, nursing home occupancy is also in a standstill in other European countries [4]. 
Concurrently with the increased occupation, various authors have highlighted an ageing trend in residential populations, partially explained by the ageing of the overall population $[7,8,17]$. In our cohort, the median age of non-IOP experienced a modest increase throughout the study period; conversely, the median age of IOP significantly increased from 83 years in 2011 to 87 in 2017. Like age, the sex distribution among residential populations has shown an evolving pattern, which may depend on the type of residential setting [7]. In our area, the percentage of women was persistently higher among IOP than non-IOP; however, sex distribution among IOP was rather constant throughout the investigated period.

Another key element, and a constant in the health care systems of most high-income countries $[6,18]$ is the tendency to concentrate those people with higher multimorbidities in a nursing home setting, a fact that underlines the imperative need to review/update the health care approach to these centres [19].

Compared to the rest of the population $\geq 65$ years, IOP showed a higher prevalence of most chronic diseases (seven times higher in the case of dementia) and a four-times higher annual mortality. In fact, during the period analysed, mortality and morbidity, which virtually remained constant in non-IOP, increased in IOP despite a $27.5 \%$ decrease in the total number of IOP. These observations are consistent with epidemiological studies conducted in our setting, which confirm that the prevalence of IOP in end-of-life transitions is above $50 \%$, with $70 \%$ of cases suffering from advanced dementia [20,21]. In line with previous reports $[22,23]$, the prevalence of some comorbidities (including dementia) among IOP showed an increasing trend throughout the investigated period, reinforcing the idea that multimorbidity - most particularly, dementia - is an intrinsic characteristic of IOP and will be increasingly common in the residential setting. As mentioned previously [23], to improve IOP care, it is necessary to develop integrated care proposals from social and health care perspectives [24,25]. This was, in fact, one of the motivations to develop the new "Integrated medical care model for institutionalized older people" in our region, the objective of which is to improve the duration and continuity of care of these people.

Consistently with studies recently conducted in our setting [26], our results show that IOP virtually present three times more urgent acute care admissions than the rest of the population $\geq 65$ years; furthermore, our analysis revealed that the mean hospital stay of these patients is twice that of the general population of the same age range. As it has been repeatedly described in the literature, these observations confirm a close relationship between institutionalization and use of resources $[27,28]$. It is therefore unavoidable to open the debate about the suitability and benefits of these admissions for patients' health $[29,30]$, which are considered appropriate based on classic criteria [26]. In this context, it would be useful to analyse IOP hospitalizations that could be potentially prevented to better improve care planning. Likewise, the medication burden dispensed to IOP is $50 \%$ higher than to non-IOP in the same age group. This fact is of special concern since it is estimated that about $40 \%$ of this prescribing is inappropriate or suboptimal [31], at the same time causing a significant number of adverse events, hospital admissions and mortality [32].

Despite being a population with high care needs, no relevant differences were observed between IOP and non-IOP concerning the number of contacts between them and primary care teams (an increase of 0.1 visits per year), which suggest lack of preventive actions by the latter. This fact might explain, at least partially, IOP higher use of resources in acute care. However, the great variability of care models in our setting makes it difficult to draw conclusions in this sense, so studies that specifically investigate the difference regarding preventive actions between IOP and non-IOP would be necessary [33].

The results of this study must be interpreted in the context of some methodological limitations. On the one hand, it is very likely that isolated diagnoses collected in the normal course of clinical practice (and therefore subject to heterogeneous criteria), as well as morbidity groupers, do not properly capture the seriousness of clinical processes, mainly in fragile patients with comorbidity. Deepening the knowledge of the severity degree and progression of the diseases described, as well as other chronic conditions (primarily geriatric syndromes and cognitive decline), would enable to give a more accurate clinical description of IOP. Given the descriptive and population approach of the study, comparative analyses have not considered the likely more heterogeneous clinical characteristics of non-IOP-from healthy adults to those in end-of-life transitions-compared with IOP. It would be interesting to analyse paired cases with IOP and non-IOP in the future, for example, in home care programs. Finally, being a large-scale, database-dependent epidemiological study, one key element of the person-centred care process could not be addressed [34], namely their values and preferences [16], which would require a qualitative methodological approach.

\section{Conclusions}

Our analysis shows that older people institutionalized in nursing homes tend to be increasingly older and more complex than the rest of the population of the same age. This growing gap between the two groups translates into higher mortality of IOP, which in our area was four times higher than that of non-IOP.

Furthermore, the higher use of resources by acute care (especially hospitalizations) and medications of IOP suggests a deficiency of preventive actions. Taken together, our findings stress the need to rethink the care model for IOP from a social and health care perspective.

\section{List Of Abbreviations}

CHSS: Catalan Health Surveillance System

COPD: Chronic obstructive pulmonary disease

GMA: Adjusted Morbidity Groups (Spanish: Grupos de Morbilidad Ajustada)

IOP: Institutionalized older people.

SD: Standard deviation

\section{Declarations}


This study was conducted on already available data. To prevent patient identification, the data used did not contain any personal information. The study was approved by the Research Ethics Committee of UVic-UCC (ref. no. 63/2018), following the national regulatory framework on clinical research. Based on sample size and absence of personal information in the dataset used for analysis, the Ethics Committee determined that a written informed consent from each patient was unnecessary.

\section{Consent for Publication}

Not applicable

\section{Availability of Data and Materials}

The datasets used and/or analysed during the current study are available from the corresponding author on reasonable request

\section{Competing Interests}

The authors declare that they have no competing interests.

\section{Funding}

This research did not receive any funding from agencies in the public, commercial, or not-for-profit sectors.

\section{Authors' Contributions}

The study was conceived and designed by JA-N, SJS, EV, and JCC. Data were acquired and analysed by EV and MC, and JA-N, SJS, EV, and JCC made substantial contributions to data interpretation. The manuscript was first drafted by JA-N and SJS, and the subsequent versions were thoroughly revised by JA-N, SJS, EV, MC, and JCC. All co-authors approved the final version of the manuscript.

\section{Acknowledgements}

The authors would like to thank Nico Martínez Velilla for thoroughly reviewing the manuscript and i2e3 Research Institute for editing the final draft.

\section{References}

1. Sherman FT. The good news: It's our 60th Birthday The bad news: A giant, geriatric tsunami! Geriatrics. 2006;61(1):10-1.

2. World Health Organization. World report on ageing and health [Internet]. 2015 [cited 2019 Nov 10]. p. 1-260. Available from: https://www.who.int/ageing/events/world-report-2015-launch/en/

3. Ministry of Economy and Finance. Statistical Institute of Catalonia [Internet]. Official Statistics of Catalonia. 2018 [cited 2019 May 10]. Available from: https://www.idescat.cat/?lang=en

4. World Health Organization. Number of nursing and elderly home beds - European Health Information Gateway [Internet]. 2016 [cited 2019 Nov 4]. Available from: https://gateway.euro.who.int/en/indicators/hfa_491-5101-number-of-nursing-and-elderly-homebeds/visualizations/\#id=19556\&tab=table

5. Morley JE, Caplan G, Cesari M, Dong B, Flaherty JH, Grossberg GT, et al. International survey of nursing home research priorities. J Am Med Dir Assoc. 2014;15(5):309-12.

6. Gordon AL, Franklin M, Bradshaw L, Logan P, Elliott R, Gladman JRF. Health status of UK care home residents: A cohort study. Age Ageing. 2014;43(1):97103.

7. M. Smith - Office for National Statistics. Changes in the Older Resident Care Home Population between 2001 and 2011 - Office for National Statistics [Internet]. 2014 [cited 2020 Apr 23]. Available from:

https://www.ons.gov.uk/peoplepopulationandcommunity/birthsdeathsandmarriages/ageing/articles/changesintheolderresidentcarehomepopulationbetw 08-01

8. Ness J, Ahmed A, Aronow WS. Demographics and payment characteristics of nursing home residents in the United States: A 23-year trend. Journals Gerontol - Ser A Biol Sci Med Sci. 2004;59(11):1213-7.

9. Gordon AL, Bowman C. Understanding mortality in care facilities-the role of good data. Age Ageing. 2018;47(2):162-3.

10. Cancio JM, Vela E, Santaeugènia S, Clèries M, Inzitari M, Ruiz D. Long-term Impact of Hip Fracture on the Use of Healthcare Resources: a PopulationBased Study. Journal of the American Medical Directors Association. 2018 Oct 1;

11. Cancio JM, Vela E, Santaeugènia S, Clèries M, Inzitari M, Ruiz D. Influence of demographic and clinical characteristics of elderly patients with a hip fracture on mortality: A retrospective, total cohort study in North-East Spain. Bone. 2018 Dec;117:123-9.

12. Dueñas-Espín I, Vela E, Pauws S, Bescos C, Cano I, Cleries M, et al. Proposals for enhanced health risk assessment and stratification in an integrated care scenario. BMJ Open. 2016;6(4):e010301.

13. Monterde D, Vela E, Clèries M, Grupo colaborativo GMA. [Adjusted morbidity groups: A new multiple morbidity measurement of use in Primary Care]. Atención Primaria. 2016;48(10):674-82.

14. Sanford AM, Orrell M, Tolson D, Abbatecola AM, Arai H, Bauer JM, et al. An International Definition for "Nursing Home." J Am Med Dir Assoc. 2015;16(3):181-4. 
15. Instituto Nacional de Estadística. Censos de Población y Viviendas 2011 Población residente en establecimientos colectivos [Internet]. 2013 [cited 2019 Nov 20]. Available from: http://www.ine.es/prensa/np777.pdf

16. Díaz-Veiga P, Sancho M. Residencias, crisis y preferencias de las personas mayores. Rev Esp Geriatr Gerontol. 2013;48(3):101-2.

17. Peace SM. The development of residential and nursing home care in the United Kingdom. In: Katz JS, Peace SM, editors. End of Life in Care Homes: a Palliative Approach. Oxford University Press; 2003. p. 15-42.

18. Harris-Kojetin L, Sengupta M, Park-Lee E, Valverde R, Caffrey C, Rome V, et al. Long-Term Care Providers and services users in the United States: data from the National Study of Long-Term Care Providers, 2013-2014. Vital Health Stat 3. 2016;3(38):1-106.

19. Gordon AL, Goodman C, Davies SL, Dening T, Gage H, Meyer J, et al. Optimal healthcare delivery to care homes in the UK: a realist evaluation of what supports effective working to improve healthcare outcomes. Age Ageing. 2018;(January):1-9.

20. Gómez-Batiste X, Martínez-Muñoz M, Blay C, Amblàs-Novellas J, Vila L, Costa X, et al. Prevalence and characteristics of patients with advanced chronic conditions in need of palliative care in the general population: A cross-sectional study. Palliat Med. 2014;28(4):302-11.

21. Amblàs-Novellas J, Murray SA, Espaulella J, Martori JC, Oller R, Martinez-Muñoz M, et al. Identifying patients with advanced chronic conditions for a progressive palliative care approach: a cross-sectional study of prognostic indicators related to end-of-life trajectories. BMJ Open. 2016;6(9):e012340.

22. Agency for Healthcare Research \& Quality. Comparison of Characteristics of Nursing Homes and Other Residential Long-Term Care Settings for People With Dementia [Internet]. [Internet]. Evidence-based Practice Center Systematic Review Protocol Project. 2011 [cited 2020 Apr 23]. Available from: https://effectivehealthcare.ahrq.gov/products/dementia-nursing-home-characteristics/research-protocol

23. Gordon AL, Goodman C, Dening T, Davies S, Gladman JRF, Bell BG, et al. The optimal study: Describing the key components of optimal health care delivery to UK care home residents: A research protocol. J Am Med Dir Assoc. 2014;15(9):681-6.

24. Miller SC, Lima JC, Intrator O, Martin E, Bull J, Hanson LC. Palliative Care Consultations in Nursing Homes and Reductions in Acute Care Use and Potentially Burdensome End-of-Life Transitions. J Am Geriatr Soc. 2016;64(11):2280-7.

25. Hamel MB. Investing in Better Care for Patients Dying in Nursing Homes. N Engl J Med. 2015;372(19):1858-9.

26. Sánchez-pérez I, Comes N, Romero L, Prats G. Urgencias hospitalarias procedentes de residencias geriátricas de una comarca: evolución , características y adecuación. 2018;32(1):27-34.

27. Gozalo P, Plotzke M, Mor V, Miller SC, Teno JM. Changes in Medicare Costs with the Growth of Hospice Care in Nursing Homes. N Engl J Med. 2015;372(19):1823-31.

28. Smith P., Sgerkaw-Johnson, C.Ariti, C. BM. Focus on hospital admissions from care homes. Qual Watch. 2015;The Health.

29. Amblàs Novellas J, Panicot JE, Pueyo CB, Brunet NM, Lucchetti d'Aniello GE, Arisa AA, et al. [Topics and considerations on reducing hospital admission: from evidence to practice]. Rev Esp Geriatr Gerontol. 2013;48(6):290-6.

30. Porter ME. What Is Value in Health Care? N Engl J Med. 2010;363:2477-81.

31. Gallagher P, Barry P, O'Mahony D. Inappropriate prescribing in the elderly. Vol. 32, Journal of Clinical Pharmacy and Therapeutics. 2007. p. $113-21$.

32. Perri M, Menon AM, Deshpande AD, Shinde SB, Jiang R, Cooper JW, et al. Adverse outcomes associated with inappropriate drug use in nursing homes. Ann Pharmacother. 2005;39(3):405-11.

33. Iliffe S, Davies SL, Gordon AL, Schneider J, Dening T, Bowman C, et al. Provision of NHS generalist and specialist services to care homes in England: Review of surveys. Prim Heal Care Res Dev. 2016;17(2):122-37.

34. Koren MJ. Person-centered care for nursing home residents: The culture-change movement. Health Aff. 2010;29(2):1-6.

\section{Tables}

Table 1: Comparative results of demographic, morbidity and mortality characteristics between institutionalized (IOP) and non-institutionalized older people (non-IOP). Years 2011, 2013, 2015 and 2017. 


\begin{tabular}{|c|c|c|c|c|c|c|c|c|c|c|c|c|c|}
\hline & & \multicolumn{3}{|c|}{2011} & \multicolumn{3}{|c|}{2013} & \multicolumn{3}{|c|}{2015} & \multicolumn{3}{|c|}{2017} \\
\hline & & IOP & n-IOP & $p$ & IOP & n-IOP & $p$ & IOP & n-IOP & $p$ & IOP & n-IOP & $p$ \\
\hline \multicolumn{2}{|l|}{ No. of cases } & 93,038 & $1,258,204$ & - & 78,458 & $1,320,726$ & & 68,545 & $1,367,075$ & & 67,456 & $1,405,167$ & \\
\hline \multicolumn{2}{|l|}{ Percentage } & 6.9 & 93.1 & - & 5.6 & 94.4 & - & 4.8 & 95.2 & - & 4.6 & 95.4 & - \\
\hline \multirow[t]{2}{*}{ Age (years) } & Mean (SD) & $\begin{array}{c}82.02 \\
(8.4)\end{array}$ & $\begin{array}{l}75.59 \\
(7.6)\end{array}$ & \multirow[t]{2}{*}{$<0.0001^{\mathrm{a}}$} & $\begin{array}{l}83.75 \\
(8.0)\end{array}$ & $\begin{array}{l}75.56 \\
(7.7)\end{array}$ & \multirow[t]{2}{*}{$<0.0001^{a}$} & $\begin{array}{c}85.08 \\
(7.8)\end{array}$ & $\begin{array}{l}75.64 \\
(7.8)\end{array}$ & \multirow[t]{2}{*}{$<0.0001^{a}$} & $\begin{array}{l}85.95 \\
(7.6)\end{array}$ & $\begin{array}{l}75.67 \\
(7.8)\end{array}$ & \multirow[t]{2}{*}{$<0.0001^{\mathrm{a}}$} \\
\hline & Median (IQR) & $\begin{array}{c}83(76- \\
88)\end{array}$ & $\begin{array}{c}75(69- \\
81)\end{array}$ & & $\begin{array}{c}85(79- \\
90)\end{array}$ & $\begin{array}{c}76(70- \\
82)\end{array}$ & & $\begin{array}{c}86(81- \\
91)\end{array}$ & $\begin{array}{c}74(69- \\
81)\end{array}$ & & $\begin{array}{c}87(82- \\
91)\end{array}$ & $\begin{array}{c}74(69- \\
81)\end{array}$ & \\
\hline \multirow[t]{2}{*}{ Sex } & Men (\%) & 31.36 & 43.25 & \multirow[t]{2}{*}{$<0.0001$} & 29.29 & 43.52 & \multirow[t]{2}{*}{$<0.0001$} & 28.48 & 43.57 & \multirow[t]{2}{*}{$<0.0001$} & 27.89 & 43.71 & \multirow[t]{2}{*}{$<0.0001$} \\
\hline & Women (\%) & 68.64 & 56.75 & & 70.91 & 56.48 & & 71.52 & 56.43 & & 72.11 & 56.29 & \\
\hline \multicolumn{2}{|l|}{ Deaths (\%) } & 11.74 & 3.10 & $<0.0001$ & 14.1 & 3.40 & $<0.0001$ & 18.2 & 3.24 & $<0.0001$ & 20.46 & 3.13 & $<0.0001$ \\
\hline \multicolumn{14}{|l|}{ MORBIDITY } \\
\hline \multicolumn{2}{|c|}{ Diabetes (\%) } & 31.4 & 26.04 & $<0.0001$ & 29.68 & 24.75 & $<0.0001$ & 30.77 & 25.28 & $<0.0001$ & 32.15 & 25.75 & $<0.0001$ \\
\hline \multicolumn{2}{|c|}{ Heart failure (\%) } & 18.2 & 9.38 & $<0.0001$ & 21.49 & 9.43 & $<0.0001$ & 25.8 & 10.26 & $<0.0001$ & 28.73 & 10.74 & $<0.0001$ \\
\hline \multicolumn{2}{|l|}{ COPD (\%) } & 17.78 & 13.78 & $<0.0001$ & 18.00 & 13.27 & $<0.0001$ & 19.40 & 14.34 & $<0.0001$ & 20.77 & 15.14 & $<0.0001$ \\
\hline \multicolumn{2}{|c|}{ Hypertension (\%) } & 84.59 & 74.11 & $<0.0001$ & 74.85 & 65.34 & $<0.0001$ & 78.08 & 66.30 & $<0.0001$ & 80.22 & 66.55 & $<0.0001$ \\
\hline \multicolumn{2}{|c|}{ Chronic kidney disease (\%) } & 15.33 & 10.59 & $<0.0001$ & 18.99 & 10.86 & $<0.0001$ & 24.70 & 13.46 & $<0.0001$ & 29.98 & 15.99 & $<0.0001$ \\
\hline \multicolumn{2}{|l|}{ Asthma (\%) } & 6.09 & 5.49 & $<0.0001$ & 6.55 & 5.89 & $<0.0001$ & 7.12 & 6.51 & $<0.0001$ & 8.11 & 7.09 & $<0.0001$ \\
\hline \multicolumn{2}{|c|}{ Dementia (\%) } & 33.39 & 6.61 & $<0.0001$ & 35.82 & 4.55 & $<0.0001$ & 42.08 & 4.50 & $<0.0001$ & 46.47 & 4.58 & $<0.0001$ \\
\hline \multicolumn{2}{|c|}{ Cirrhosis (\%) } & 1.43 & 1.41 & 0.5 & 1.18 & 1.11 & 0.459 & 1.31 & 1.3 & 0.878 & 1.43 & 1.43 & 0.998 \\
\hline \multicolumn{2}{|c|}{ Depression (\%) } & 29.84 & 1793 & $<0.0001$ & 29.9 & 17.28 & $<0.0001$ & 33.69 & 19.13 & $<0.0001$ & 40.72 & 22.05 & $<0.0001$ \\
\hline $\begin{array}{l}\text { Mental heal } \\
\text { patient (\%) }\end{array}$ & chronic & 6.85 & 2.83 & $<0.0001$ & 10.07 & 3.25 & $<0.0001$ & 12.71 & 3.63 & $<0.0001$ & 15.36 & 4.28 & $<0.0001$ \\
\hline Stroke (\%) & & 19.31 & 9.09 & $<0.0001$ & 22.78 & 8.87 & $<0.0001$ & 27.24 & 9.82 & $<0.0001$ & 31.16 & 10.77 & $<0.0001$ \\
\hline Ischemic he & rt disease (\%) & 21.66 & 15.37 & $<0.0001$ & 14.89 & 11.55 & $<0.0001$ & 15.65 & 11.86 & $<0.0001$ & 16.22 & 12.22 & $<0.0001$ \\
\hline Neoplasia & & 19.99 & 19.65 & 0.012 & 19.54 & 18.40 & $<0.0001$ & 20.18 & 19.26 & $<0.0001$ & 22.66 & 21.42 & $<0.0001$ \\
\hline $\begin{array}{l}\text { Chronic mu } \\
\text { diseases } \\
\text { (\%) }\end{array}$ & uloskeletal & 58.2 & 54.47 & $<0.0001$ & 61.62 & 55.54 & $<0.0001$ & 66.68 & 60.46 & $<0.0001$ & 74.73 & 67.22 & $<0.0001$ \\
\hline Osteoporosi & $(\%)$ & 19.33 & 16.04 & $<0.0001$ & 17.88 & 14.43 & $<0.0001$ & 20.59 & 15.54 & $<0.0001$ & 24.24 & 16.77 & $<0.0001$ \\
\hline Osteoarthrit & (\%) & 43.64 & 37.03 & $<0.0001$ & 46.04 & 36.8 & $<0.0001$ & 50.36 & 40.26 & $<0.0001$ & 56.08 & 43.5 & $<0.0001$ \\
\hline Arthritis $(\%$ & & 5.82 & 4.32 & $<0.0001$ & 6.09 & 4.33 & $<0.0001$ & 7.45 & 5.83 & $<0.0001$ & 9.41 & 7.55 & $<0.0001$ \\
\hline Chronic pai & (\%) & 1.16 & 0.56 & $<0.0001$ & 1.46 & 0.84 & $<0.0001$ & 2.64 & 1.35 & $<0.0001$ & 4.41 & 1.9 & $<0.0001$ \\
\hline Malnutritior & $(\%)$ & 0.52 & 0.17 & $<0.0001$ & 0.79 & 0.25 & $<0.0001$ & 1.21 & 0.34 & $<0.0001$ & 1.55 & 0.41 & $<0.0001$ \\
\hline Pressure ulc & r (\%) & 2.34 & 0.50 & $<0.0001$ & 3.40 & 0.59 & $<0.0001$ & 4.96 & 0.76 & $<0.0001$ & 5.67 & 0.86 & $<0.0001$ \\
\hline
\end{tabular}

COPD: Chronic Obstructive Pulmonary Disease. IOP: Institutionalized Older People. non-IOP: non-Institutionalized Older People. IQR: interquartile range $\left(25^{\text {th }}\right.$ and $75^{\text {th }}$ percentiles). SD: standard deviation

${ }^{\mathrm{a} B o t h}$ T-test and Mann-Whitney U test.

Table 2: Comparative results of the use of resources between institutionalized and non-institutionalized men and women. Year 2017. 


\begin{tabular}{|c|c|c|c|c|c|c|c|c|c|}
\hline \multicolumn{3}{|l|}{ HEALTH RESOURCE USE } & \multicolumn{3}{|c|}{ IOP } & \multicolumn{3}{|c|}{ non-IOP } & \multirow[b]{2}{*}{$P^{\mathrm{a}}$} \\
\hline & & & Men & Women & Overall & Men & Women & Overall & \\
\hline \multirow[t]{2}{*}{ Visits to primary care } & \multicolumn{2}{|c|}{ Mean (SD) } & $\begin{array}{l}13.74 \\
(15.5)\end{array}$ & $\begin{array}{l}11.76 \\
(13.3)\end{array}$ & $\begin{array}{l}12.26 \\
(14.0)\end{array}$ & $\begin{array}{l}11.78 \\
(13.7)\end{array}$ & $\begin{array}{l}12.44 \\
(11.7)\end{array}$ & $\begin{array}{l}12.15 \\
(11.7)\end{array}$ & \multirow[t]{2}{*}{$<0.0001$} \\
\hline & Medi & (IQR) & $9(4-18)$ & $8(3-16)$ & $8(3-16)$ & $9(4-15)$ & $8(4-16)$ & $9(4-16)$ & \\
\hline \multicolumn{3}{|l|}{ Admissions to acute care hospitals (\%) } & 63.03 & 41.58 & 47.56 & 32.13 & 24.19 & 27.66 & $<0.0001$ \\
\hline \multicolumn{3}{|l|}{ Urgent admissions to acute care hospitals (\%) } & 52.31 & 35.72 & 40.34 & 16.45 & 11.41 & 13.61 & $<0.0001$ \\
\hline \multicolumn{3}{|l|}{ Patients with >1 urgent admission to hospital (\%) } & 11.79 & 7.05 & 3.55 & 3.30 & 2.05 & 2.34 & $<0.0001$ \\
\hline \multirow[t]{2}{*}{ Length of hospital stay (days) } & \multicolumn{2}{|c|}{ Mean (SD) } & $4.20(9.9)$ & $2.62(7.3)$ & $3.06(8.1)$ & $1.67(7.0)$ & $1.08(5.2)$ & $1.34(6.1)$ & \multirow[t]{2}{*}{$<0.0001$} \\
\hline & Medi & $(I Q R)$ & $0(0-4)$ & $0(0-1)$ & $0(0-1)$ & $0(0-0)$ & $0(0-0)$ & $0(0-0)$ & \\
\hline \multirow{2}{*}{\multicolumn{2}{|c|}{ Length of hospital stay (only acute care hospitals) (days) }} & Mean (SD) & $\begin{array}{c}11.24(13 \\
(4)\end{array}$ & $\begin{array}{l}9.41 \\
(11.2)\end{array}$ & $\begin{array}{l}10.03 \\
(12.1)\end{array}$ & $\begin{array}{l}8.14 \\
(13.7)\end{array}$ & $\begin{array}{l}6.34 \\
(11.2)\end{array}$ & $7.21(12.5)$ & \multirow[t]{2}{*}{$<0.0001$} \\
\hline & & $\begin{array}{l}\text { Median } \\
\text { (IQR) }\end{array}$ & $7(3-15)$ & $6(2-12)$ & $7(2-13)$ & $4(0-10)$ & $2(0-8)$ & $3(0-9)$ & \\
\hline \multirow{2}{*}{\multicolumn{2}{|c|}{$\begin{array}{l}\text { Length of hospital stay for urgent admissions (days) (over all } \\
\text { admissions) }\end{array}$}} & Mean (SD) & $3.73(9.0)$ & $2.40(6.8)$ & $2.77(7.5)$ & $1.25(5.9)$ & $0.83(4.5)$ & $1.01(5.1)$ & \multirow[t]{2}{*}{$<0.0001$} \\
\hline & & $\begin{array}{l}\text { Median } \\
\text { (IQR) }\end{array}$ & $0(0-3)$ & $0(0-0)$ & $0(0-0)$ & $0(0-0)$ & $0(0-0)$ & $0(0-0)$ & \\
\hline \multirow{2}{*}{\multicolumn{2}{|c|}{$\begin{array}{l}\text { Length of hospital stay for urgent admissions (days) (over urgent } \\
\text { admissions) }\end{array}$}} & Mean (SD) & $\begin{array}{l}11.39 \\
(12.6)\end{array}$ & $\begin{array}{l}9.66 \\
(10.7)\end{array}$ & $\begin{array}{l}10.24 \\
(11.4)\end{array}$ & $\begin{array}{l}11.28 \\
(14.0)\end{array}$ & $\begin{array}{l}9.99 \\
(12.2)\end{array}$ & $\begin{array}{l}10.65 \\
(13.2)\end{array}$ & \multirow[t]{2}{*}{$\begin{array}{r}<0.0001 \text { । } \\
0.286^{b}\end{array}$} \\
\hline & & $\begin{array}{l}\text { Median } \\
\text { (IQR) }\end{array}$ & $8(3-15)$ & $7(3-12)$ & $7(3-13)$ & $7(3-14)$ & $7(3-12)$ & $7(3-13)$ & \\
\hline \multirow{2}{*}{\multicolumn{2}{|c|}{ Admissions to emergency services }} & Mean (SD) & $1.21(1.7)$ & $0.89(1.4)$ & $0.89(1.5)$ & $0.60(1.3)$ & $0.56(1.2)$ & 0.58 & \multirow{2}{*}{$\begin{array}{r}0.006 \mid \\
<0.0001^{b}\end{array}$} \\
\hline & & $\begin{array}{l}\text { Median } \\
\text { (IQR) }\end{array}$ & $1(0-2)$ & $0(0-1)$ & $0(0-1)$ & $0(0-1)$ & $0(0-1)$ & $0(0-1)$ & \\
\hline \multirow{2}{*}{\multicolumn{2}{|c|}{ Visits to specialized hospital care }} & Mean (SD) & $2.18(3.8)$ & $1.45(2.9)$ & $1.65(3.2)$ & $3.44(5.1)$ & $2.95(4.5)$ & $3.17(4.7)$ & \multirow[t]{2}{*}{$<0.0001$} \\
\hline & & $\begin{array}{l}\text { Median } \\
\text { (IQR) }\end{array}$ & $1(0-3)$ & $0(0-2)$ & $0(0-2)$ & $2(0-5)$ & $1(0-4)$ & $1(0-4)$ & \\
\hline \multicolumn{3}{|l|}{ Visits to outpatient mental health services (\%) } & 14.22 & 8.99 & 10.45 & 4.99 & 9.43 & 7.48 & $<0.0001$ \\
\hline Admissions to nursing skilled facilities (\%) & & & 34.97 & 24.99 & 27.77 & 7.69 & 7.21 & 7.42 & $<0.0001$ \\
\hline
\end{tabular}




\begin{tabular}{|c|c|c|c|c|c|c|c|c|}
\hline \multirow[t]{2}{*}{ Dispensed medicines (No. of packages) } & Mean (SD) & $\begin{array}{l}93.98 \\
(79.9)\end{array}$ & $\begin{array}{l}90.37 \\
(67.3)\end{array}$ & $\begin{array}{l}91.38 \\
(71.1)\end{array}$ & $\begin{array}{l}56.52 \\
(65.3)\end{array}$ & $\begin{array}{l}56.15 \\
(56.7)\end{array}$ & $56.31(60.6)$ & \multirow[t]{2}{*}{$<0.0001$} \\
\hline & $\begin{array}{l}\text { Median } \\
\text { (IQR) }\end{array}$ & $\begin{array}{c}82(49- \\
122)\end{array}$ & $\begin{array}{c}80(47- \\
119)\end{array}$ & $\begin{array}{l}81(47 \\
(120)\end{array}$ & $\begin{array}{c}43(17- \\
78)\end{array}$ & $\begin{array}{c}44 \text { (18- } \\
80)\end{array}$ & $44(17-79)$ & \\
\hline \multirow[t]{2}{*}{ Prescribed medicines (different active ingredients) } & Mean (SD) & $\begin{array}{l}12.07 \\
(5.5)\end{array}$ & $\begin{array}{l}11.60 \\
(5.5)\end{array}$ & $\begin{array}{l}11.73 \\
(5.5)\end{array}$ & $7.63(5.6)$ & $8.24(5.6)$ & $7.97(5.6)$ & \multirow[t]{2}{*}{$<0.0001$} \\
\hline & $\begin{array}{l}\text { Median } \\
\text { (IQR) }\end{array}$ & $12(8-15)$ & $11(8-15)$ & $11(8-15)$ & $7(3-11)$ & $8(4-12)$ & $7(4-11)$ & \\
\hline
\end{tabular}

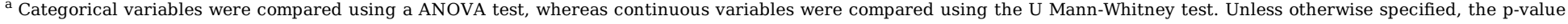
corresponds to both, man/woman and IOP/non-IOP comparisons.

${ }^{\mathrm{b}} \mathrm{p}$-values correspond to man/woman | IOP/non-IOP

IOP: Institutionalized Older People. non-IOP: non-Institutionalized Older People. IQR: interquartile range $\left(25^{\text {th }}\right.$ and $75^{\text {th }}$ percentiles). SD: standard deviation.

\section{Additional Material}

File name: IOP - Additional file 1.pdf

Title: Appendix

Content: Figures A1 and A2, which show the age and sex distribution of IOP and non-IOP, and the frequency of comorbidities of IOP

\section{Figures}




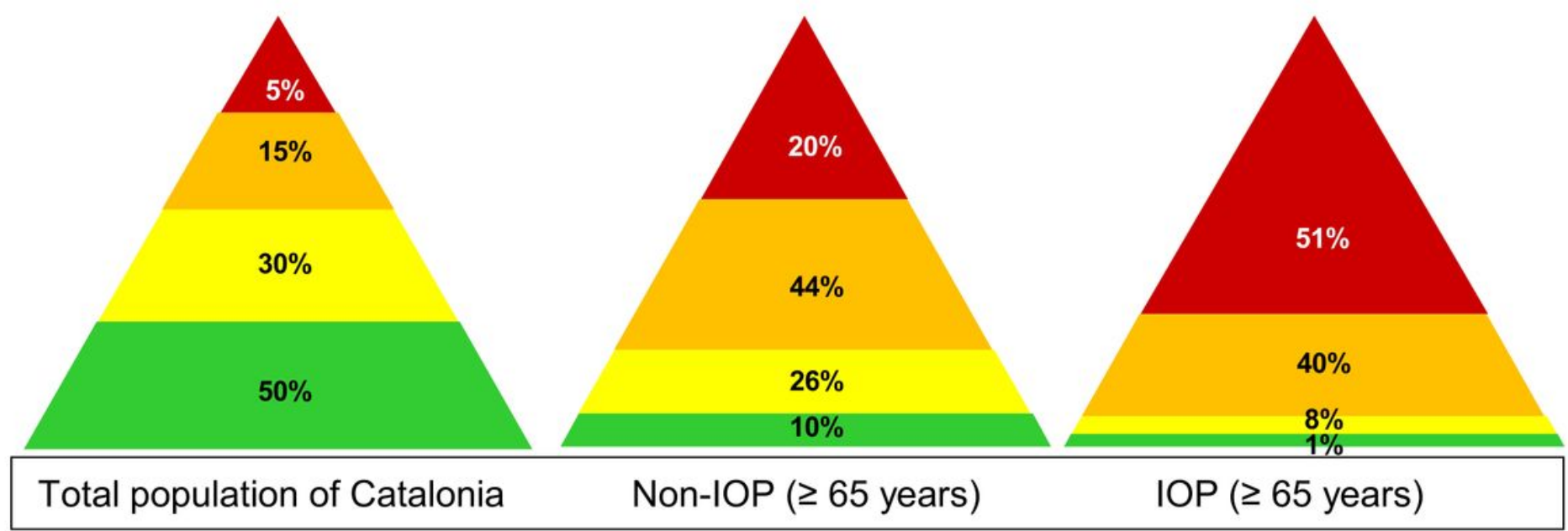

High-risk population

Low-risk population

Moderate-risk population

Initial-risk population

Figure 1

Comparative result of multimorbidity (GMA)-based stratification between the general population of Catalonia, non-institutionalized (non-IOP) $\geq 65$ years and institutionalized older people $\geq 65$ years (IOP) 2017

\section{Supplementary Files}

This is a list of supplementary files associated with this preprint. Click to download.

- IOPAdditionalfile1.pdf 